\title{
Antimicrobial properties of medicinal plants; The new therapeutic aspect of Valeriana
}

\section{officinalis}

\section{Zohre Eftekhari ${ }^{1 *}$}

${ }^{1}$ Research \& Production Complex, Quality Control Department, Pasteur Institute of Iran, Alborz- Iran

\section{Abstract}

\section{*Correspondence to: \\ Dr. Zohre Eftekhari \\ z_eftekhari@pasteur.ac.ir}

Received: 22 March 2020

Accepted: 15 April 2020

ePublished: 16 June 2020

Keywords: Valeriana officinalis, Antibiotic, Anti-microbial
The increased use of antibiotics and chemicals with various side effects is now persuading scientists to develop natural substitutes with appropriate effectiveness and protection for humans. V. officinalis rhizomes contain two major constituent groups, including volatile oil sesquiterpens and valpotriates. Valerenic acid can be used to in different disorders such as depression, chronic anxiety, and sleep disorders on the basis of previous studies4. Based on previous literatures, the valerenic acid component had antimicrobial effects on different microorganisms such as Helicobacter pylori, Staphylococcus aureus and Candida albicans and its methanolic extract functions were dose-dependent. Since the antimicrobial activity of $\mathrm{V}$. officinalis in the total extract was correlated with abundant monoterpenoids and sesquiterpenoids, more research on various aspects of pharmaceutical effects is suggested.

\section{Citation:}

Eftekhari Z. Antimicrobial properties of medicinal plants; The new therapeutic aspect of Valeriana officinalis. Plant Biotechnology Persa. 2020; 2(1): 59-60.

\section{Dear editor:}

The increased use of antibiotics and chemicals with various side effects is now persuading scientists to develop natural substitutes with appropriate effectiveness and protection for humans. The outbreak of the world's emerging and re-emerging infectious diseases has prompted pharmaceutical companies to develop new medicines. Valerian is one of the worldwide recognized medicinal herbs that consume abundantly for the treatment of various human diseases and disorders. The Valerianaceae family contains 10 genera and approximately 300 species [1]. It has widely cultivated for commercial purposes in some regions of Iran, including ornamental, edible, and medical [1]. V.officinalis rhizomes contain two major constituent groups, including volatile oil sesquiterpens and valpotriates. Both active components are present in the hypodermis in large thin-cells at the roots, and rhizomes periphery [2]. Although there are still some disagreements about the relative efficacy of various groups of V.officinalis compounds, it is widely accepted that valerenic acid is the most important biologically active component $[3,4]$. Valerenic acid and its derivatives are commonly considered to contribute to valerian extracts ' pharmaceutical effect, characterized and isolated by different analytical methods [5]. Valerenic acid can be used to in different disorders such as depression, chronic anxiety, and sleep disorders on the basis of previous studies [4]. Based on previous literatures, the valerenic acid component had antimicrobial effects on different microorganisms such as Helicobacter pylori, Staphylococcus aureus and Candida albicans and its methanolic extract functions were dose-dependent [6-8]. Since the antimicrobial activity of V. officinalis in the total extract was correlated with abundant monoterpenoids and sesquiterpenoids, more research on various aspects of pharmaceutical effects is suggested.

\section{Acknowledgment}

This study was financially supported by Pasteur Institute of Iran, Alborz- Iran.

\section{Authors' contribution}

All authors contributed equally to the manuscript.

\section{Conflicts of interest}

The authors declared no competing interests.

Copyright (c) 2020 The Author(s). This is an open-access article distributed under the terms of the Creative Commons Attribution License (http://creativecommons.org/licenses/by/4.0), which permits unrestricted use, distribution, and reproduction in any medium, provided the original work is properly cited. 


\section{Ethical considerations}

Ethical issues (including plagiarism, data fabrica $\neg$ tion, double publication and etc.) have been completely ob $\neg$ served by author.

\section{Funding/Support \\ None}

\section{References:}

1. Murti K, Kaushik M, Sangwan Y, Kaushik A. Pharmacological properties of Valeriana officinalis-a review. Pharmacologyonline. 2011; 3:641-6.

2. Dong F-W, Li F, Ren J-J, Zhao C-M, Diao H-L, Li B-J, et al. Sesquiterpenoids from the roots and rhizomes of Valeriana amurensis and their effects on NGF-induced neurite outgrowth in PC12 cells. Nat Prod Res . 2019: 1-6.

3. Wi凶niewski J, Szczepanik M, Kołodziej B, Król B. Plantation methods effects on common valerian (Valeriana officinalis) yield and quality. J Animal Plant Sci. 2016; 26: 177-84.

4. Yeo Y-S, Nybo SE, Chittiboyina AG, Weerasooriya AD, Wang Y-H, Góngora-Castillo E, et al. Functional identification of valerena-1, 10-diene synthase, a terpene synthase catalyzing a unique chemical cascade in the biosynthesis of biologically active sesquiterpenes in Valeriana officinalis. J Biol Chem. 2013; 288(5): 3163-73.

5. Wang J, Zhao J, Liu H, Zhou L, Liu Z, Wang J, et al. Chemical analysis and biological activity of the essential oils of two valerianaceous species from China: Nardostachys chinensis and Valeriana officinalis. Molecules. 2010; 15(9): 6411-22.

6. Nybo SE, Saunders J, McCormick SP. Metabolic engineering of Escherichia coli for production of valerenadiene. J Biotechnol. 2017; 262: 60-6.

7. Khademian R, Karimzadeh F, Moradi P, Asghari B. Anti-microbial Properties of Valeriana officinalis, Satureja bachtiarica and Thymus daenensis Methanolic Extracts against Helicobacter pylori. J Pharm Res Int. 2019: 1-7.

8. Cowan MM. Plant products as antimicrobial agents. Clin Microbiol Rev. 1999; 12(4): 564-82. 